\title{
Ensaio: Educação e a Tolerância como dever ético
}

\author{
Carlos Roberto da Silveira*
}

Un hombre del pueblo de Neguá, en la costa de Colombia, pudo subir al alto cielo. A la vuelta, contó. Dijo que había contemplado, desde allá arriba, la vida humana. $Y$ dijo que somos un mar de fueguitos. El mundo es eso -reveló- Un montón de gente, un mar de fueguitos. Cada persona brilla con luz propia entre todas las demás. No hay dos fuegos iguales. Hay fuegos grandes y fuegos chicos y fuegos de todos los colores. Hay gente de fuego sereno, que ni se entera del viento, y gente de fuego loco, que llena el aire de chispas. Algunos fuegos, fuegos bobos, no alumbran ni queman; pero otros arden la vida con tantas ganas que no se puede mirarlos sin parpadear, y quien se acerca, se enciende (Eduardo Galeano).

Estamos às vésperas do final de mais um ano, o de 2015 e, quase quinze anos já se passaram adentrando este novo milênio... Novo milênio, no entanto, nosso assunto é velho e versa sobre a tolerância. Aqui neste momento, nossa pretensão é promover reflexões a tal ponto, quem sabe, de se chegar ao lume para repensar, discutir e perscrutar a Educação dos nossos jovens, as teorias e pensamentos atuais que envolvam as mais diversas atitudes e ações intolerantes, inclusive as nossas próprias.

Há exatos 20 anos, em 16 de novembro de 1995 em Paris, a Conferência Geral da Organização das Nações Unidas para a Educação, Ciência e Cultura (UNESCO), junto com os seus Estados membros aprovavam a "Declaração de Princípios Sobre a Tolerância" (DPST). No preâmbulo desta declaração, retoma-se artigos da "Declaração Universal dos Direitos do Homem" (DUDH) de 10 de dezembro 1948, sobre o direito e a liberdade de pensamento, de consciência, de religião, de opinião e de expressão e acrescenta que a educação deve favorecer a compressão, a tolerância e a amizade entre nações de todos grupos étnicos e religiosos, pois:

Alarmados pela intensificação atual da intolerância, da violência, do terrorismo, da xenofobia, do nacionalismo agressivo, do racismo, do anti-semitismo, da exclusão, da marginalização e da discriminação contra minorias nacionais, étnicas, religiosas e linguísticas, dos refugiados, dos trabalhadores migrantes, dos imigrantes e dos grupos vulneráveis da sociedade $e$ também pelo aumento dos atos de violência $e$ de intimidação cometidos contra pessoas que exercem sua liberdade de opinião e de expressão, todos comportamentos que ameaçam a consolidação da paz e da democracia no plano nacional $e$ internacional e constituem obstáculos para $o$ desenvolvimento, ressaltando que incumbe aos Estados membros desenvolver e fomentar o respeito dos direitos humanos $e$ das liberdades fundamentais de todos, sem distinção fundada sobre a raça, o sexo, a língua, a origem nacional, a religião ou incapacidade e também combater a intolerância [e, por isso aprovam a Declaração] (DPST, 1997,p.10).

Assim sendo, a DPST declara que a tolerância é respeito, aceitação da diversidade cultural, abertura do espírito para a comunicação, para liberdade de pensamento e harmonia da diferença. É dever ético e necessidade de ordem política e jurídica. Quanto à educação, afirma que é o meio mais eficaz de prevenção à intolerância. Deve-se ensinar os seus direitos e liberdades para assegurar o respeito, incentivar a vontade para proteger direitos e liberdades. "As políticas e programas de educação devem contribuir para o desenvolvimento da compreensão, da solidariedade e da tolerância entre os indivíduos, entre os grupos étnicos, sociais, culturais, religiosos, linguísticos e as nações" (DPST, 1997, p15).

Ao aludirmos às datas acima, evocamos momentos, 15 anos de um novo milênio, 20 anos da DPST, 67 anos DUDH, olhamos para trás e vemos este passado relativamente próximo, mas que evoca um assunto velho, o da tolerância. Se pensarmos, sobre este ano de 2015 que ainda não findou, dizemos "vésperas"1, ou "tarde", aqui tarde intolerante, ou melhor "noite" que não se encerra. Embora seja "tarde", vivemos ainda neste ano muitíssimo marcado pela intolerância que nem se precisa mencionar, pois ainda estão frescos em nossas memórias, tantas mortes e feridos, tantos

\footnotetext{
*Docente do Programa de Pós-Graduação Stricto Sensu da USF. Endereço eletrônico: carlosilveir@ yahoo.com.br.
} 
atos de violências que destroem quaisquer tentativas de racionalidade, ou se quiserem, de "beleza" ou "amor".

Contudo, ao se falar do tempo, o conceito de tolerância possui uma idade muito mais avançada e se constitui de uma longa história no pensamento ocidental. De acordo com Henrique Cláudio de Lima Vaz, o termo nasce no século XV com o Cardeal Nicolau de Cusa (1401-1464), no contexto de diálogo das grandes religiões e que fortaleceu no século seguinte devido à divisão religiosa e guerras de religião. Já no século XVIII, o termo ganha força com a Ilustração que estende o conceito para os grupos discriminados da sociedade civil, as mulheres, as crianças, os negros, os índios das colônias americanas e os judeus. Nesse período de tolerância civil, John Locke foi o grande filósofo teórico [em especial com a obra: Carta acerca da tolerância]. Já no plano jurídico, Cesare Beccaria, com Dos delitos e das penas (1764), erige as bases fundamentais do Direito Penal moderno (Cf. LIMA VAZ, 1991, p.94). O conceito de tolerância na contemporaneidade acrescentou novos embasamentos nas vozes de Karl Popper, Michael Walzer, John Rawls, Norberto Bobbio, dentre outros.

Ao se falar dos problemas do contexto religioso, político, e dos grupos discriminados, concordamos com Norberto Bobbio (1904-2004) de que são formas diferentes de intolerância. Neste momento, não se tem a pretensão de trazer de forma mais aprofundada as ideias deste pensador, mas lançar algumas fagulhas para que essas nos incendeie. Bobbio $(2004$, p.86) declara que a tolerância de crenças, políticas e opiniões diversas implicam em um "discurso sobre a verdade e a compatibilidade teórica ou prática da verdade até mesmo contrapostas". Já a outra deriva de um preconceito, de opiniões ou conjunto de opiniões que são aceitas de modo acrítico, sem discussões advindos da tradição.

De certo, também a convicção de possuir a verdade pode ser falsa e assumir a forma de um preconceito. Mas é um preconceito que se combate de modo inteiramente diverso: não se podem pôr no mesmo plano os argumentos utilizados para convencer o fiel de uma Igreja ou o seguidor de um partido [político] a admitir a presença de outras confissões e de outros partidos, por um lado, e, por outro, os argumentos que se devem aduzir para convencer um branco a conviver pacificamente com um negro, um turinês com um sulista, a não discriminar social e legalmente um homossexual, etc. A questão fundamental que foi posta sempre pelos defensores da tolerância religiosa ou política é deste teor: como são compatíveis, teórica e praticamente, duas verdades opostas? A questão que deve pôr a si mesmo o defensor da tolerância em face dos diferentes é outra: como é possível demonstrar que o mal-estar diante de uma minoria ou diante do irregular, do anormal, mais precisamente do "diferente", deriva de preconceitos inveterados, de formas irracionais, puramente emotivas, de julgar os homens e os eventos? (BOBBIO, 2004, p.86).

Assim sendo, as intolerâncias fundadas na crença de uma verdade absoluta e a da discriminação e preconceito são assuntos complexos e carecem de muitos diálogos, pois diante de tanta violência cotidiana, não podemos eximir de que uma "tolerância negativa" ronda diante de nós e que, de certa forma, tornamos intolerantes ${ }^{2}$. Não precisamos de uma arma que dispare, de uma faca que corte, de uma pedra que se jogue contra o outro. Nossos olhares por vezes matam, vozes ferem e desprezam, ações escravizam pelos ciúme e inveja, daí nossas razões míopes, "tolerantes" às executam.

Para Bobbio (2004, p. 87) a tolerância não implica na renúncia à própria convicção,

mas implica pura e simplesmente a opinião (a ser eventualmente revista em cada oportunidade concreta, de acordo com as circunstâncias e as situações) de que a verdade tem tudo a ganhar quando suporta o erro alheio, já que a perseguição, como a experiência histórica o demonstrou com frequência, em vez de esmagá-lo, reforça-o.

Na história, a tolerância sempre foi acusada de ceticismo, visto que esta deveria ser tolerante porque não existem verdades. No entanto, é possível ser tolerante sem ser cético, é possível a compreensão com outro sem perder as suas crenças. Bobbio (2004) declara que o cético seria aquele que não importa que a fé e a crença triunfem. Já o tolerante diante das razões práticas, aquele que dá importância ao triunfo da verdade, mesmo que seja a sua e, considera-se tolerante tendo por fim último combater os erros, os danos que possam causar a 
intolerância. Tal medida prática do tolerante frente ao diverso, ao outro, são essenciais, como aponta Bobbio (2004, p.87) para que haja o "princípio da reciprocidade, sobre o qual se fundam todas as transações, todos os compromissos, todos os acordos, que estão na base de qualquer convivência pacífica (...)".

Mas, para além da prática tolerante, ele pensa que podemos avançar mais ainda a favor da tolerância através de uma razão moral absoluta, ou seja, a do respeito à pessoa alheia, da benevolência, na qual não se precisa renunciar a própria verdade ou a indiferença da própria verdade. Eis aqui, a forma de governo democrático, do direito de todo o homem, das Declarações Universais do homem. As pessoas devem chegar à verdade através da convicção íntima e não por imposição.

Desse ponto de vista, a tolerância não é apenas um mal menor, não é apenas a adoção de um método de convivência preferivel a outro, mas é a única resposta possível à imperiosa afirmação de que a liberdade interior é um bem demasiadamente elevado para que não seja reconhecido, ou melhor, exigido (BOBBIO, 2004, p.88).

Norberto Bobbio em sua obra Elogio Della Mitezza e Altri Scritti Morali, traduzida no Brasil como Elogio da Serenidade e Outros Escritos Morais, escolheu o termo mitezza para fundamentar o que ele chama de cidadãos democráticos comprometidos no combate ao preconceito através da prática cotidiana da tolerância. O termo não possui uma tradução correspondente na língua portuguesa e optou-se por "Serenidade". Este termo foi se formando através de conotações de seus pensamentos sobre a Filosofia Moral. Ele inicia o texto Elogio da Mitezza refletindo sobre a ética da atualidade, na qual acredita que a ética das virtudes praticamente desapareceu. Sobre o termo, este pode significar moderado, sereno, leve, suave, afável, compreensível, complacente, mas não é a mansidão, é virtude social para o coletivo e não individual. Mitezza é mais que respeito ao outro é mais que tolerância, é a construção de uma sociedade que reconhece o outro, como outro e o faz de forma ativa. Tal serenidade se opõe ao abuso de poder, a arrogância, a prepotência e insolência. A tolerância "é a única suprema potência (...) que consiste em deixar o outro ser aquilo que é" (BOBBIO, 2002, p.35).
Umberto Eco, em seu livro Cinco escritos Morais, aponta a existência de uma espécie de intolerância, que ele chama de "intolerância selvagem", aquela que é impermeável a qualquer crítica e pelas quais os intelectuais não podem lutar, porque diante da animalidade pura, qualquer pensamento crítico fica sem força. Assim, sempre é "tarde demais" e a intolerância torna-se doutrina. Mas o que fazer? Quais as saídas dessa animalidade? Como superar tal desafio em prol da tolerância? Ele escreve:

Educar para a tolerância adultos que atiram uns nos outros por motivos étnicos e religiosos é tempo perdido. Tarde demais. A intolerância selvagem deve ser, portanto, combatida em suas raízes, através de uma educação constante que tenha início na mais tenra infância, antes que possa ser escrita em um livro, e antes que se torne uma casca comportamental e dura demais (ECO, 2000, p.117).

Mesmo que seja "tarde" esperamos que não seja "tarde demais". Que Hésperos, estrela vespertina clareie nossas noites. Que um dia, como Hésperos sejamos lembrados também pela nossa bondade. Que Eósforo ou Phosphorus (Fósforo), estrela matutina mantenha acesa em nós a chamada "tolerância positiva". Que a Noite seja mais calma e não de pura treva. Que Vênus firme-se forte nos nossos horizontes e propague a sua beleza. Que a educação cultive frutos sensíveis, serenos, virtuosos, "desde a mais tenra idade" e que os adultos sejam realmente bons jardineiros. Que a mitezza conforte a tolerância e que esta tolerância abarque até os intolerantes, pois "O sereno é, ao contrário, aquele que 'deixa o outro ser o que é', ainda quando o outro é o arrogante, o insolente, o prepotente" (BOBBIO, 2002, p.40).

Como conta Eduardo Galeano, somos um mar de fogos e não existe dois fogos iguais. Cada pessoa possui luz própria, umas grandes, pequenas e de diversas cores. Há gente de fogo sereno que nem fica sabendo do vento, gente de fogo louco que espalha pelo ar muitas faíscas. Existem fogos bobos que não iluminam nem queimam. Porém, existem gentes cujos fogos ardem a vida com tanta vontade, que não podemos olhá-los sem pestanejar, e quem se aproxima se incendeia.

\section{Notas}


1 Véspera em latim é vespera, vésper para os romanos. Na Mitologia Grega é Hésperos

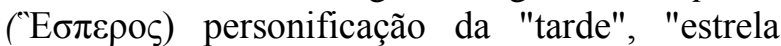
vespertina", filho de Eos (Aurora, deusa do amanhecer) e de Céfalo, um mortal. Seu meio-

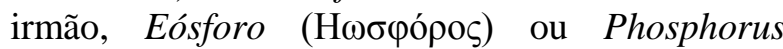
$\left.\left(\Phi \omega \sigma \varphi \rho_{\rho}\right) \varsigma\right)$ é a personificação da "estrela matutina", filho de Eos e de Astreu (deus das estrelas). No período mítico não imaginavam que o Planeta Vênus, em homenagem a Afrodite (deusa da beleza e do amor), fossem as estrelas de Héspero e Eósforo que, somente foram identificados no período helenístico pelos gregos. Ruth Guimarães, (1999, 117) conta uma outra versão, a de que esta "estrela da tarde" era filho do Monte Atlas e quando estava nesta montanha apreciando as estrelas foi surpreendido por uma tempestade e então ele desapareceu. Ele era amado por todos os homens devido a sua bondade, então afirmaram que ele se transformara nesta estrela que anuncia a cada dia o repouso da Noite (Noite é a personificação das trevas que sucedem o Dia, filha do Caos).

2 Bobbio alerta que a tolerância tem suas boas razões, mas não podemos esquecer que a intolerância também pode ter suas boas razões: "Tolerância em sentido positivo se opõe a intolerância (religiosa, política, racial), ou seja, à indevida exclusão do diferente. Tolerância em sentido negativo se opõe à firmeza nos princípios, ou seja, à justa ou devida exclusão de tudo o que pode causar dano ao indivíduo ou à sociedade. Se as sociedades despóticas de todos os tempos e de nosso tempo sofrem de falta de tolerância em sentido positivo, as nossas sociedades democráticas e permissivas sofrem de excesso de tolerância em sentido negativo, de tolerância no sentido de deixar as coisas como estão, de não interferir, de não se escandalizar nem se indignar com mais nada" (BOBBIO, 2004, p.89).

\section{Referências}

BOBBIO, Norberto. A era dos direitos. Trad. Carlos Nelson Coutinho; Apresentação de Celso Lafer. Rio de Janeiro: Editora Campus/Elsevier, 2004.

BOBBIO, Norberto. Elogio da serenidade e outros ensaios morais. Trad. M.A. Nogueira. São Paulo: Unesp, 2002.

DECLARAÇÃO DE PRINCÍPIOS SOBRE A TOLERÂNCIA. Trad. Universidade de São Paulo, São Paulo: USP/UNESCO, 1997.

ECO, Umberto. Cinco Escritos Morais. Trad. Eliana Aguiar. Rio de Janeiro: Record, 2000.

GALEANO, Eduardo. Somos um mar de foguinhos. Sangue Latino,-YouTube- Vídeo, somos um mar de pequenos fogos. https://www.youtube.com/watch?v=pBIIEgVSVMg

GUIMARÃES, Ruth. Dicionário da Mitologia Grega. São Paulo: Editora Cultrix, 1999.

LIMA VAZ, Henrique Cláudio de. Antropologia Filosófica. V.1. São Paulo: Edições Loyola, 1991.

LOCKE, John. Carta acerca da tolerância. Trad. de Anoar Aiex. Col. Os Pensadores. $3^{\text {a }}$ Ed. São Paulo: Abril Cultural, 1983.

\section{Sobre o autor}

Carlos Roberto da Silveira é Mestre em Filosofia (concentração em Ética) pela PUC-Campinas e Doutor em Filosofia pela PUC-SP. Pós-Doutor pela USF e professor do Programa de Pós-Graduação em Educação da USF.

Recebido em outubro de 2015.

Aprovado em novembro de 2015. 